\title{
Assessment of land-use change on streamflow using GIS, remote sensing and a physically-based model, SWAT
}

\author{
JOSÉ YURE G. DOS SANTOS ${ }^{1}$, RICHARDE MARQUES DA SILVA ${ }^{2}$, \\ JOSÉ G. CARVALHO NETO ${ }^{1}$, SUZANA MARIA G. L. MONTENEGRO ${ }^{1}$, \\ CELSO A. G. SANTOS ${ }^{2} \&$ ALEXANDRO M. SILVA ${ }^{2}$ \\ 1 Federal University of Pernambuco, Department of Civil Engineering, 50670-901 Recife, PE, Brazil \\ 2 Federal University of Paraiba, Department of Civil and Environmental Engineering, 58051-900 João Pessoa, PB, \\ Brazil \\ celso@ct.ufpb.br
}

\begin{abstract}
This study aims to assess the impact of the land-use changes between the periods 1967-1974 and 1997-2008 on the streamflow of Tapacurá catchment (northeastern Brazil) using the Soil and Water Assessment Tool (SWAT) model. The results show that the most sensitive parameters were the baseflow, Manning factor, time of concentration and soil evaporation compensation factor, which affect the catchment hydrology. The model calibration and validation were performed on a monthly basis, and the streamflow simulation showed a good level of accuracy for both periods. The obtained $\mathrm{R}^{2}$ and Nash-Sutcliffe Efficiency values for each period were respectively 0.82 and 0.81 for $1967-1974$, and 0.93 and 0.92 for the period 1997-2008. The evaluation of the SWAT model response to the land cover has shown that the mean monthly flow, during the rainy seasons for 1967-1974, decreased when compared to 1997-2008.
\end{abstract}

Key words surface runoff; impacts of landscape; Tapacurá catchment, Brazil

\section{INTRODUCTION}

Climate change is predicted to considerably affect the hydrology of northeastern Brazil. Streamflow characteristics, both mean and interannual variability, of the Tapacurá catchment have far-reaching implications for the Recife Metropolitan Region (Silva et al. 2012), especially during periods of water scarcity, such as during and following the major drought of 1998 in this region. Analysis of this event exposed a profound range of implications, including environmental and economic effects, social impacts, and impacts on government entities and on a wider range of public policies.

Studies about the influence of land-use change on streamflow at the basin scale have been reported by several authors (e.g. Kundzewicz et al. 2008, Montenegro and Ragab 2012, Braga et al. 2013, Silva et al. 2013). Previous studies on the hydrological response to climate change in basins in northeastern Brazil drew attention to the risk of worsening water availability and the impact on the hydrology and social aspects in the region. We have examined this need for more sophisticated modelling procedures in the context of climate change to expose the strengths and weaknesses of linking global and regional climate models to a runoff model to calculate the discharge consistent with a future climate scenario. Thus, this study aims to assess the influence of land-use change on the streamflow through GIS and remote sensing techniques coupled with the SWAT model.

Predictions of long-term impacts of climate and land-cover change on streamflow are important to study different environmental conditions. Analysis of hydrological responses to climate and land-use change in a basin can be performed by combining a calibrated basin-scale model with historical data or future scenarios.

\section{MATERIAL AND METHODS}

\section{Study area description}

The Tapacurá catchment is one of the main sub-catchments that supply the Recife Metropolitan Region, and one of the water resource management planning units for that region, Pernambuco state. The Tapacurá catchment covers an area of about $470 \mathrm{~km}^{2}$, and is located in the Zona da Mata region in the state of Pernambuco, northeastern Brazil, between coordinates $7^{\circ} 58^{\prime} 0^{\prime \prime}$ and $8^{\circ} 13^{\prime} 0^{\prime \prime} \mathrm{S}$, and $35^{\circ} 5^{\prime} 0^{\prime \prime}$ and $35^{\circ} 30^{\prime} 0^{\prime \prime} \mathrm{W}$ (Fig. 1). 


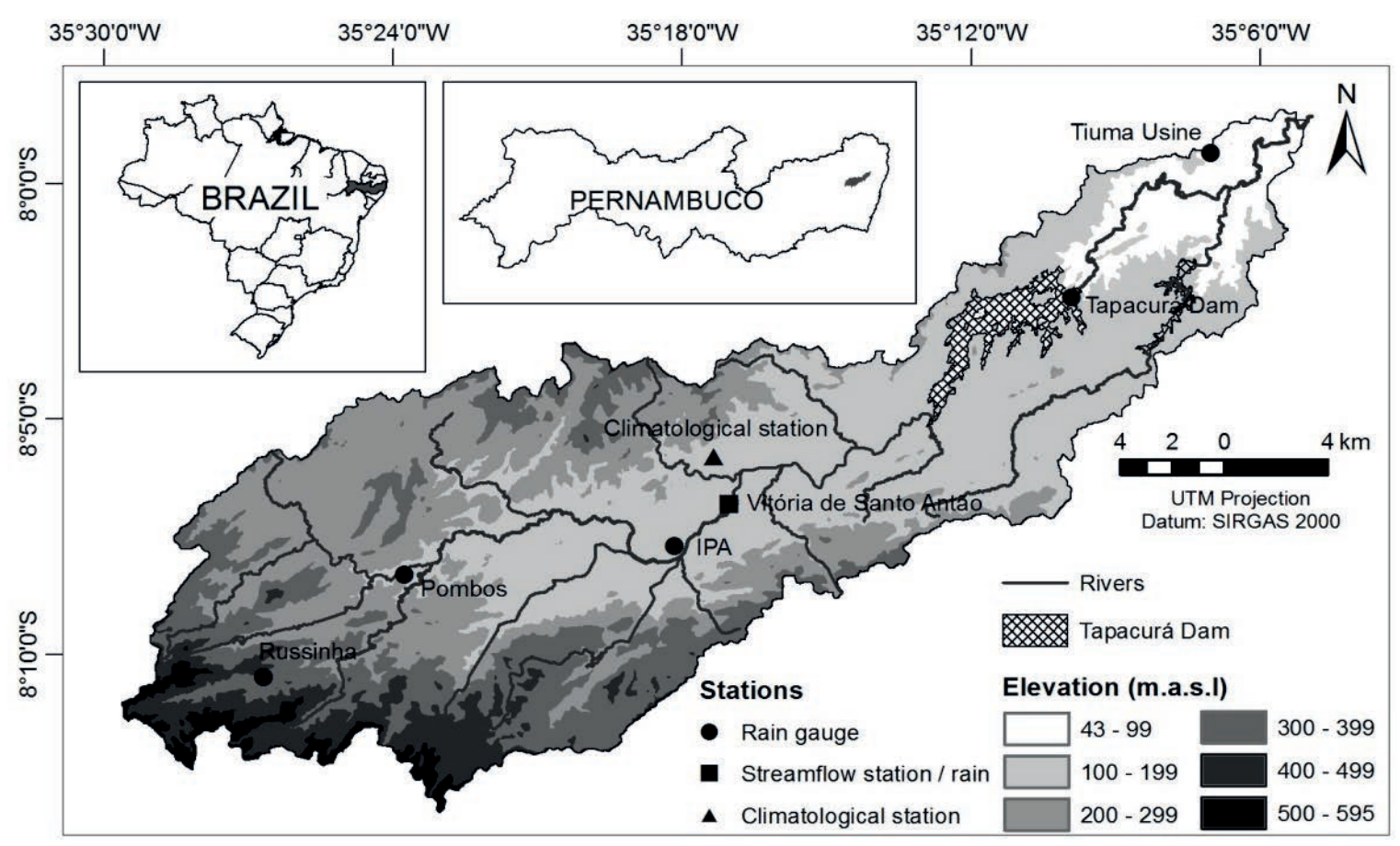

Fig. 1 Location of Tapacurá catchment in Brazil and the rainfall, streamflow and climatological gauges.

The Tapacurá catchment has high hills, deep valleys, large plateaus and gullies. Agriculture and livestock are the main activities of the people in the area. The rainfall is characterized by an annual precipitation ranging from 800 to $1800 \mathrm{~mm}$ with the rainy season between March and August. Rainfall is higher in the east and is usually not well distributed over the year; dry and wet periods often alternate rapidly, resulting in a highly erratic and unpredictable river flow regime. Rapid surface flows dominate the hydrographs. The climate is tropical, hot and humid. The maximum daily rainfall in the area is $175 \mathrm{~mm}$, whereas the annual average temperature is $27^{\circ} \mathrm{C}$, with a daily temperature range of $25-32^{\circ} \mathrm{C}$ (Silva et al. 2010).

\section{Datasets}

The basic datasets that are required by the hydrological model are topographic, climatic, stream flow, soil and land-use data. In order to identify the cover changes, multispectral imagery was used. Topography is defined by a digital elevation model (DEM), which describes the elevation of any point in a given area at a specific spatial resolution. The DEM is one of the essential inputs required by SWAT to delineate the catchment into a number of sub-catchments. The DEM is used to analyse the drainage pattern of the watershed, slope, stream length and width of channel within the catchment. The 30-m spatial resolution DEM used in this study was obtained from the Brazil National Institute for Space Research (http://www.dsr.inpe.br/topodata).

Daily precipitation data were collected from six rainfall gauges distributed within the study area (Tiuma Usine, Russinha, Pombos, IPA, Vitória de Santo Antão and Tapacurá Dam). Daily wind speed, relative humidity, as well as maximum, minimum and mean air temperature data were collected at one climatological station (Escola Agrotécnica) (Fig. 1). SWAT was calibrated manually following a multistep procedure as recommended by Arnold et al. (2012), based on streamflow data from January 1997 to December 2008, using the data from a gauging station at Vitória de Santo Antão, located in sub-catchment \#8 (Fig. 1) through the trial and error method and adjusting the calculated and observed runoff data for the same period. This technique allows the optimization of two or more objective functions at the same time, which is useful in the case of distributed models because the results can be compared at more than one point over the basin. Manual calibration attempted to minimize total flow (minimized average annual percentage bias), accompanied by visual inspection of daily hydrographs and duration of daily flow curves. 


\section{Land-use assessment}

The land-cover data for the period 1967-1974 were obtained from aerial photos (SUDENE 1972) and for 1997-2008 from Landsat-5 multispectral imagery. The imagery used to create land-cover data for 1967-1974 and 1997-2008 were obtained at a spatial resolution of $30 \mathrm{~m}$, but both images were collected in January and February, i.e. within 23 days of each other, hence there is no seasonal difference. In this study, a total of seven land-cover classes are considered. These are caatinga (48\%), agriculture (39\%), rain forest $(9 \%)$, water $(2 \%)$ and urban areas $(1 \%)$ for the period 1967-1974, and agriculture (39\%), livestock $(39 \%)$, sugarcane $(11 \%)$, rain forest $(6 \%)$ urban areas $(2 \%)$, water $(2 \%)$ and caatinga (1\%) for the period 1997-2008. Two multichannel imageries were used in this research for the investigation of land-use change. The images were acquired in the same season in order to minimize the impacts of seasonal differences of vegetation.

\section{Hydrological modelling}

Many basin-scale hydrologic and water quality models have been developed in recent years (Yan et al. 2013). The Soil and Water Assessment Tool (SWAT) is a comprehensive, semi-distributed river basin model that requires a large number of input parameters, which complicates the model parameterization and calibration. The SWAT is one of the most suitable models for simulating streamflow under land use and management scenarios (Behera and Panda 2006). A great number of SWAT applications have been used to study hydrology in small or large catchments in different regions of the world. It is a physically-based, distributed, continuous daily time step parameter model designed to predict the impact of land management practices on water, sediment and agricultural chemical yields in large and complex watersheds with varying soil, land use and management conditions over long periods of time. SWAT can be used to analyse small or large catchments by discretizing them into sub-basins, which are then further subdivided into hydrological response units (HRUs) each having homogeneous land use, soil types and slopes. The SWAT system embedded within GIS can integrate various spatial environmental data, including information about soil, land cover, climate and topographical features. Several calibration techniques have been developed for SWAT, including manual calibration procedures and automated procedures using the shuffled complex evolution method and other common methods.

\section{RESULTS AND DISCUSSION}

\section{Calibration and validation of SWAT for Tapacurá catchment}

To analyse the impact of climate and land-cover change on the hydrology over 40 years, SWAT was used to simulate the scenarios 1967-1974 and 1997-2008. The SWAT receives daily input data, but operates with daily and monthly output intervals. In this study, the monthly output intervals were used to better graphically represent the results. The consistency of the simulated and measured values is clear. The Nash-Sutcliffe Efficiency (NSE) and $\mathrm{R}^{2}$ values for the monthly calibration and validation are listed in Table 1 . All of the NSE and $\mathrm{R}^{2}$ values for streamflow data are greater than 0.8 , which suggests a very good model performance (Moriasi et al. 2007). The root mean square error (RMSE), which measures the amplitude of the error, also shows a reasonable fit of the simulated and observed streamflow. Thus, it can be noted that the model achieved a satisfactory simulation. The hydrograph distribution also shows better fitting between simulated and observed streamflow. Observed mean precipitation is $1020 \mathrm{~mm}$ in 1967-1974 and $865 \mathrm{~mm}$ in 1997-2008. It decreased by $154 \mathrm{~mm}$ in this period. However, the mean runoff is $1.82 \mathrm{~m}^{3} / \mathrm{s}$ in $1967-1974$ and $1.59 \mathrm{~m}^{3} / \mathrm{s}$ in $1997-2008$. It decreased by $0.23 \mathrm{~m}^{3} / \mathrm{s}$. If we compare the difference between simulated and observed runoff in those two periods, we find that the difference is less than the NSE value.

The calibration results for the monthly streamflow in 1967-1974 and 1997-2008 can be seen in Fig. 2(a) and (b). Statistical evaluation revealed that the model was able to explain at least $79 \%$ of the variability in the measured streamflow with $\mathrm{R}^{2}=0.82$ and $\mathrm{NSE}=0.81$ (for 1967-1974), $\mathrm{R}^{2}=$ 0.93 and NSE $=0.92$ (for 1997-2008), showing a reasonably good agreement. Thus, the model 
shows good agreement between measured and simulated streamflows for both the calibration and validation period. As expected, the surface runoff generation showed an upward trend generally following the pattern of the rainfall. Overall, the consistency between the results of the simulation and the measured values, as well as the high NSE and $\mathrm{R}^{2}$ values, indicated that the calibrated model could describe monthly streamflow. Thus, the SWAT model, using the optimal parameters, was successfully employed to evaluate the hydrological consequences of land-use changes.

Table 1 Descriptive statistics of measured and simulated monthly streamflow in the Tapacurá catchment.

\begin{tabular}{|c|c|c|c|c|c|c|}
\hline \multirow[t]{2}{*}{ Statistics } & \multicolumn{2}{|c|}{$1967-1974$} & \multicolumn{2}{|c|}{ 1997-2008 } & \multicolumn{2}{|c|}{ Observed Rainfall } \\
\hline & \multicolumn{2}{|c|}{$\left(\mathrm{m}^{3} / \mathrm{s}\right)$} & \multicolumn{2}{|c|}{$\left(\mathrm{m}^{3} / \mathrm{s}\right)$} & \multicolumn{2}{|c|}{$(\mathrm{mm})$} \\
\hline Mean & 1.82 & 2.03 & 1.59 & 1.77 & 1020.00 & 865.00 \\
\hline Standard deviation & 3.21 & 3.32 & 3.71 & 3.94 & 6.37 & 5.90 \\
\hline Maximum & 16.96 & 17.42 & 33.93 & 35.31 & 208.00 & 134.30 \\
\hline Minimum & 0.11 & 0.00 & 0.00 & 0.00 & 0.00 & 0.00 \\
\hline RMSE & \multicolumn{2}{|c|}{1.97} & \multicolumn{2}{|c|}{1.03} & \multicolumn{2}{|c|}{-} \\
\hline NSE & \multicolumn{2}{|c|}{0.81} & \multicolumn{2}{|c|}{0.92} & \multicolumn{2}{|c|}{-} \\
\hline $\mathrm{R}^{2}$ & \multicolumn{2}{|c|}{0.82} & \multicolumn{2}{|c|}{0.93} & \multicolumn{2}{|c|}{-} \\
\hline
\end{tabular}
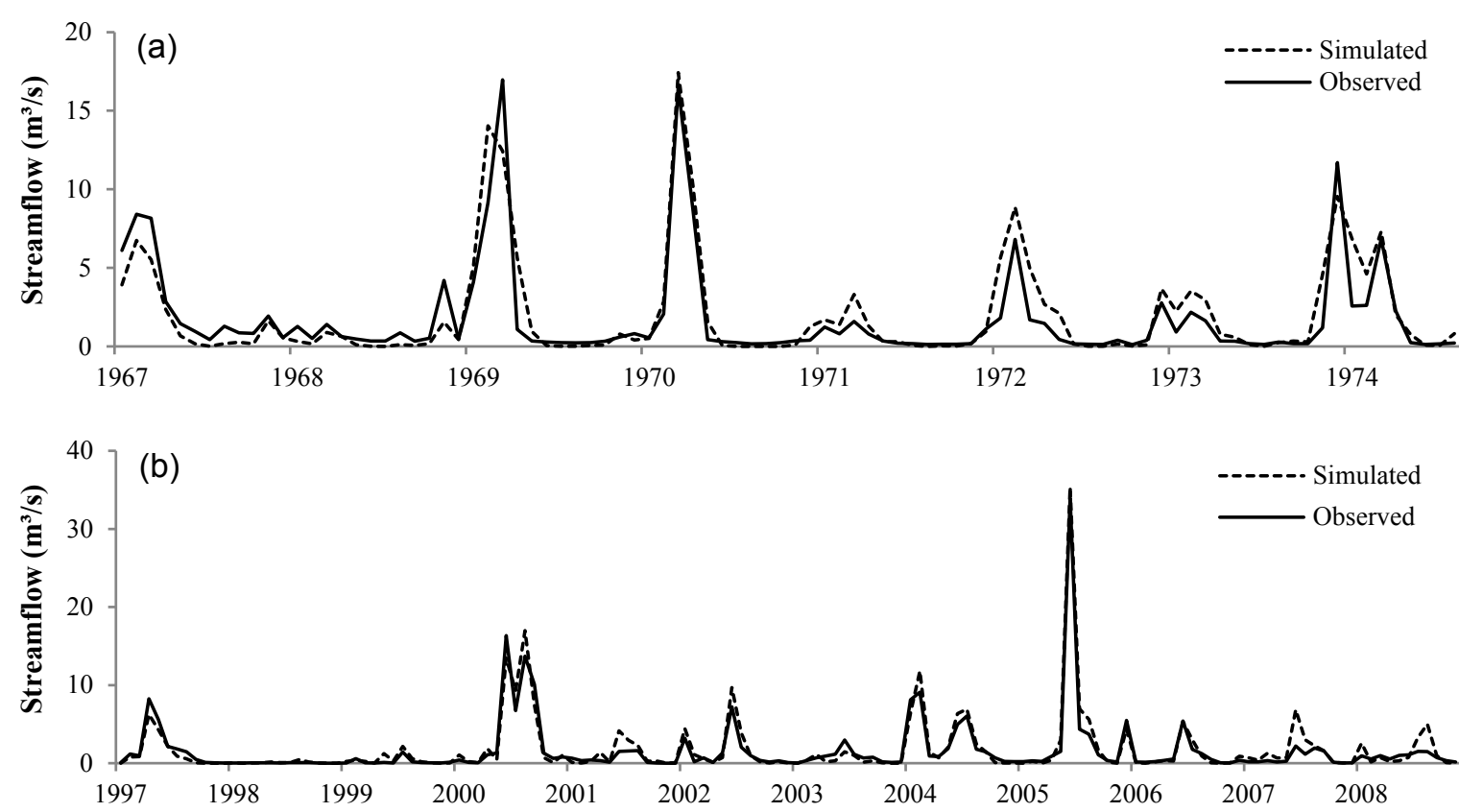

Fig. 2 Simulated versus observed monthly streamflow in the Tapacurá catchment: (a) calibration for period 1967-1974, and (b) calibration for period 1997-2008.

The streamflow is an integrator of climate processes, both spatially and temporally. Since there is essentially no change in basin storage for each year, what goes in as precipitation must come out at streamflow. It is shown that the magnitude and temporal variation of the simulated runoff values matched closely with the observed ones for the 23 years; however, the timing of the peaks of observed and simulated runoff did not match well. The model over-predicted some high runoff values during the wet season in a few years, and under-predicted some dry years, which cannot be fully explained. A possible reason for these discrepancies could be the limitations of the SCS-CN method, which, when used with the SWAT model, does not consider the duration and intensity of precipitation, and instead uses mean daily rainfall depths as SWAT inputs (Nie et al. 2011, Silva et al. 2013). This bias in runoff, including rainfall-runoff models, is normal and expected, and it is, at least partly, due to the fact that the models are deterministic in nature, while measured data have a significant random component that the models cannot account for within the 
deterministic framework.

\section{Land-use changes assessment}

The spatial distribution of the seven land-use types between 1967-1974 and 1997-2008 are shown in Fig. 3. The area and percentage of total area of land use during the past four decades in the Tapacurá catchment are shown in Table 2. The results obtained for 1967-1974 reveal that caatinga (48\%) and agriculture (39\%) are the most representative land covers in the catchment. For the second period, the distribution of land cover shows that most of the catchment is covered by agriculture (39\%), livestock (39\%) and sugarcane (11\%). Caatinga vegetation and rain forest decreased after 1974 , with $-97.7 \%$ and $-36.3 \%$, respectively. The area of caatinga decreased due to the change of land use from agricultural to livestock areas after 1974 in the southwestern part of the catchment, and a change from agriculture and rain forest to sugarcane, i.e. a land use characterized by monoculture. The urban area gradually expanded from $1 \%$ to $2 \%$ over the entire study period, while the proportion of livestock area increased (by 100\%) from 1967-1974 to 1997-2008. This result indicates that government policy does not have a strong impact on land use.

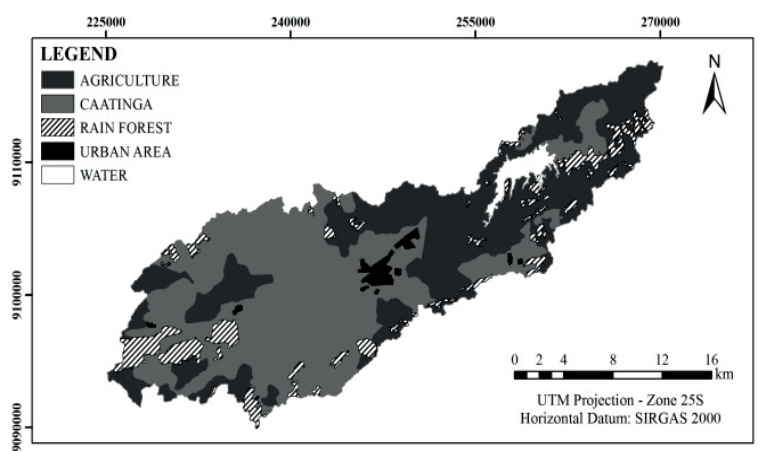

1967-1974

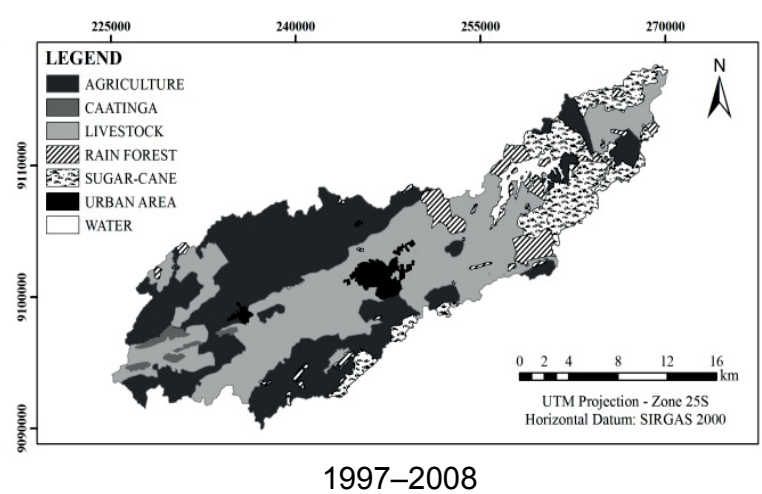

1997-2008

Fig. 3 Land-use and land-cover maps of the Tapacurá catchment for 1967-1974 and 1997-2008.

Table 2 Land-use changes in the Tapacurá catchment.

\begin{tabular}{lccccc}
\hline \multirow{2}{*}{ Land cover } & \multicolumn{2}{c}{$1967-1974$} & \multicolumn{2}{c}{$1997-2008$} & Variation of \\
\cline { 2 - 5 } & Area $\left(\mathrm{km}^{2}\right)$ & $\%$ & Area $\left(\mathrm{km}^{2}\right)$ & $\%$ & -2.0 \\
\hline Agriculture & 186 & 39 & 182 & 39 & -97.7 \\
Caatinga & 228 & 48 & 5 & 1 & +100.0 \\
Livestock & - & - & 457 & 39 & -36.3 \\
Rain forest & 41 & 9 & 26 & 6 & +100.0 \\
Sugarcane & - & - & 52 & 11 & +51.0 \\
Urban areas & 7 & 1 & 11 & 2 & +4.2 \\
Water & 10 & 2 & 11 & 2 & \\
\hline
\end{tabular}

\section{Hydrologic responses to land cover change}

The purpose of model validation is to check whether the model can predict flow for a range of time periods or conditions different to those for which the model was calibrated, i.e. that the model is applicable outside the validation sets of conditions such as for a future time period and other areas. To evaluate the model performance, both the coefficient of determination $\left(\mathrm{R}^{2}\right)$ and the (NSE) were used. The result shows that the mean wet monthly flow for 1997-2008 land cover decreased by $-12.6 \%$ when compared to the land cover in 1967-1974 (Table 1). Changes in land use occurred in all parts of the catchment but mainly in the southwestern part. Vegetation cover within the catchment has changed considerably due to human activities, mainly through the conversion of natural vegetation to agriculture, livestock and sugarcane. These changes have altered water resources through biophysical and biogeochemical processes in the soil. Through 
these land-cover changes, the biophysical and morphological characteristics of the vegetation have been modified and therefore, the changes have affected the exchange of water between the atmosphere and land surface. Compared to the land-use baseline of 1967-1974, the mean annual rainfall over the catchment was $-15.2 \%$ lower in 1997-2008. The changes in streamflow matched the land-use dynamics, particularly for the livestock and sugarcane (Table 2).

\section{CONCLUSIONS}

Use of GIS and remotely sensed data were found to be helpful to detect and analyse spatiotemporal land cover dynamics. A SWAT model for the Tapacurá catchment was calibrated for streamflow analysis. Based on the results obtained, the following conclusions are drawn: (a) the catchment experienced significant land-use change between the two analysed periods. It is concluded that the decrease in forest land and grassland was accompanied by increase in agricultural and built up areas; (b) analysis showed that the most sensitive parameter was the Initial SCS curve number II (Cn2); and (c) the hydrological model SWAT simulates the runoff reasonably with satisfactory $\mathrm{R}^{2}$ and Nash-Sutcliffe efficiency values. The model run for different land use revealed that the wet season flow increases for the most recent year, while the dry season flow decreases appreciably. This is mainly attributed to land degradation (conversion of caatinga and forest into agriculture, livestock and sugarcane), which in turn increased surface runoff during wet seasons and reduced baseflow during the dry seasons.

Acknowledgements The authors are supported by CNPq, FACEPE and MCT/CT-HIDRO/FINEP. ANA (Brazilian National Water Agency) is acknowledged for providing the database.

\section{REFERENCES}

Arnold, J. G., et al. (2012) SWAT: model use, calibration, and validation. Transactions of the ASABE 55(4), 1491-1508.

Behera, S. and Panda, R.K. (2006) Evaluation of management alternatives for an agricultural watershed in a sub-humid subtropical region using a physical process based model. Agriculture, Ecosystems \& Environment 113(1-4), 62-72.

Braga, A. C. F. M., et al. (2013). Downscaling of a global climate model for estimation of runoff, sediment yield and dam storage: A case study of Pirapama basin, Brazil. Journal of Hydrology 498(1), 46-58.

Kundzewicz, Z. W., et al. (2008) The implications of projected climate change for freshwater resources and their management. Hydrological Sciences Journal 53(1), 3-10.

Montenegro, S. M. G. L. and Ragab, R. (2012) Impact of possible climate and land use changes in the semi arid regions: A case study from North Eastern Brazil. Journal of Hydrology 434(1), 55-68.

Moriasi, D. N., et al. (2007) Model evaluation guidelines for systematic quantification of accuracy in watershed simulations. Transactions of the ASABE 50(3), 885-900.

Nie, W. M., et al. (2011) Assessing impacts of land-use changes on hydrology for the upper San Pedro watershed. Journal of Hydrology 407(1), 105-114.

Silva, R. M., et al. (2013) Erosivity, surface runoff, and soil erosion estimation using GIS-coupled runoff-erosion model in the Mamuaba catchment, Brazil. Environmental Monitoring and Assessment 185(65), 8656-8676.

Silva, R. M., Montenegro, S. M. G., and Santos, C. A. G. (2012) Integration of GIS and remote sensing for estimation of soil loss and prioritization of critical sub-catchments: a case study of Tapacurá catchment. Natural Hazards 63(3), 576-592.

Silva, R. M., et al. (2010) Spatial analysis of vegetal cover and sediment yield in Tapacurá river catchment based on remote sensing and GIS. Land Reclamation 42(1), 5-16.

SUDENE (1972) Superintendência do Desenvolvimento do Nordeste. Região Nordeste do Brasil - 1:100.000. Ministério do Interior, Brasília, DF.

Yan, B., et al. (2013) Impacts of land use change on watershed streamflow and sediment yield: an assessment using hydrologic modelling and partial least squares regression. Journal of Hydrology 484(1), 26-37. 